\title{
Correction: BNIP3 modulates the interface between B16-F10 melanoma cells and immune cells
}

\author{
Erminia Romano ${ }^{1}$, Nicole Rufo ${ }^{1}$, Hannelie Korf ${ }^{2,3}$, Chantal Mathieu ${ }^{3}$, Abhishek D. \\ Garg $^{1}$ and Patrizia Agostinis ${ }^{1}$ \\ ${ }^{1}$ Laboratory for Cell Death Research and Therapy (CDRT), Department of Cellular and Molecular Medicine, KU Leuven, \\ Leuven, Belgium \\ ${ }^{2}$ Laboratory of Hepatology, Department of Chronic Diseases, Metabolism and Ageing (CHROMETA), KU Leuven, Leuven, \\ Belgium \\ ${ }^{3}$ Laboratory of Clinical and Experimental Endocrinology (CEE), Department of Chronic Diseases, Metabolism and Ageing \\ (CHROMETA), KU Leuven, Leuven, Belgium
}

Published: December 11, 2018

Copyright: Romano et al. This is an open-access article distributed under the terms of the Creative Commons Attribution License 3.0 (CC BY 3.0), which permits unrestricted use, distribution, and reproduction in any medium, provided the original author and source are credited.

This article has been corrected: During the assembly of the Figure 1B, the flow cytometry histogram concerning ecto-CD47 expression of B16-F10 cell lines exposed to normoxic (Nor) conditions was presented incorrectly. Using the source data, a correct Figure 1B was generated and is shown below. The authors declare that these corrections do not change the results or conclusions of this paper.

\section{B}
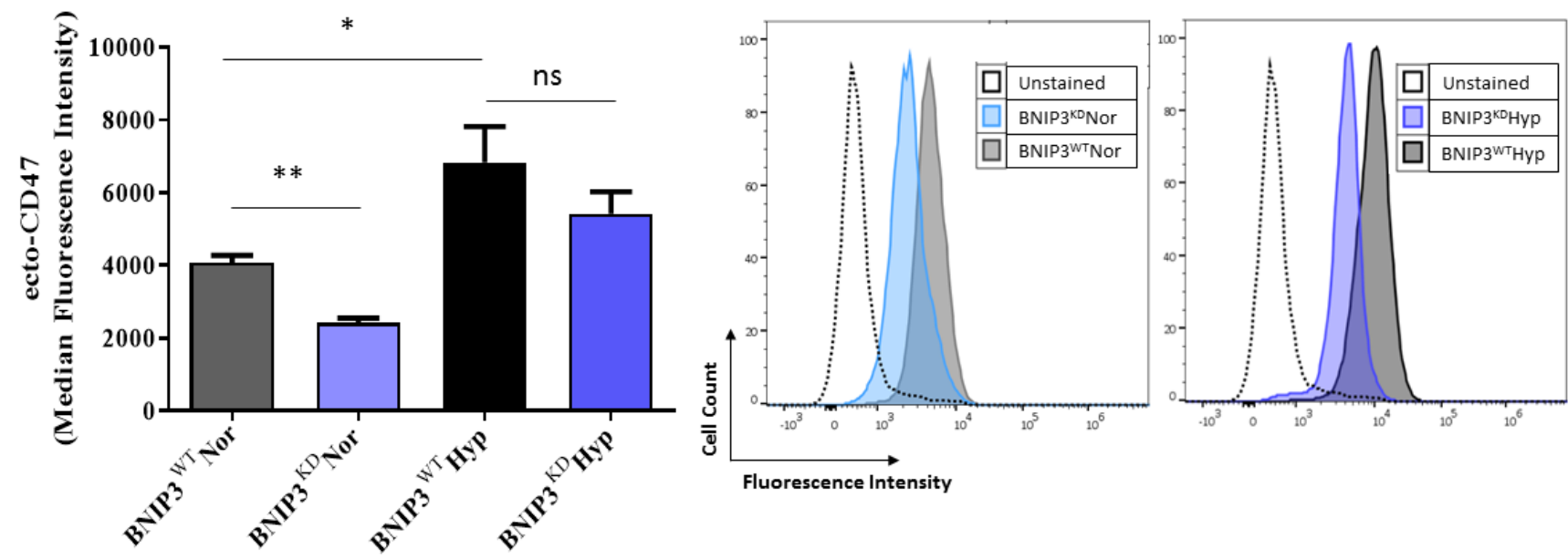

B16-F10

Figure 1: BNIP3 and hypoxia modulate the phagocytosis of B16-F10 melanoma cells by macrophages. (B) Flow Cytometrybased quantification (left panel) and representative histograms (right panel) of the level of surface CD47 (ecto-CD47) in B16-F10 cells $\left(B N I P 3^{\text {WT }}\right.$ and BNIP3 ${ }^{\mathrm{KD}}$ ) after $24 \mathrm{~h}$ of culture in normoxia (Nor) or hypoxia (Hyp). Data expressed as mean \pm SEM and analysed with Mann-Whitney's $t$-test $\left(* * p=0.0043,{ }^{*} p=0.0411, \mathrm{~ns}=\right.$ not significant $\left.[p=0.3052]\right)$ as indicated by the bar, $n=3$ independent experiments).

Original article: Oncotarget. 2018; 9:17631-17644. https://doi.org/10.18632/oncotarget.24815 